\title{
SIMULASI ENERGI IKAT DAN ENERGI DISINTEGRASI PELURUHAN UNSUR RADIOAKTIF DERET AKTINIUM BERDASARKAN MODEL INTI TETESAN CAIRAN (TELAAH KLASIK)
}

\author{
${ }^{1)}$ Maharani Karunia P, ${ }^{1)}$ Albertus Djoko Lesmono, ${ }^{1)}$ Alex Harijanto \\ ${ }^{1)}$ Program Studi pendidikan Fisika FKIP Universitas Jember \\ Email: maharanikaruniaputri@yahoo.co.id
}

\begin{abstract}
Abstrack
The purpose of this research was made simulation with Matlab application to calculate the binding energy and disintegration energy of Actinium series based of liquid drop model approach. The type of this research was experimental research. The steps were: 1) prepare literature studies of elements in the radioactive process; 2) reviewing some literatures; 3) do calculation simulation; 4) analyze and discuss the results of calculations; 5) conclude the research results. The calculation results show that the binding energy value of the Actinium Series based of liquid drop model approach is in accordance with the theory where the binding energy is directly proportional to the mass and the number of particles, so that the binding energy decreases in linear graph. The largest binding energy owned by ${ }_{92} U^{235}$ element was $1786,751 \mathrm{MeV}$. While the smallest binding energy owned by the ${ }_{81} \mathrm{Tl}^{20}$ element was 1616,311 MeV. The disintegration energy found in the radioactive actinium series has a positive value, so this is in accordance with the conditions for the occurrence of decay, which is $Q>0$. The largest disintegration energy produced from alpha decay by element ${ }_{91} \mathrm{~Pa}^{231}$ was $4.9335 \mathrm{MeV}$ and the smallest binding energy generated from beta decay by the element ${ }_{90} \mathrm{Th}^{231}$ was $0,0018 \mathrm{MeV}$.
\end{abstract}

Key word: Disintegration Energy, Binding Energy, Liquid Drop Model Approach.

\section{PENDAHULUAN}

Fisika merupakan salah satu mata pelajaran yang terdapat di sekolah. Pelajaran fisika umumnya dianggap sebagai pelajaran yang sulit dipahami oleh siswa. Beberapa alasannya adalah karena terdapat konsep abstrak yang harus dipahami dan banyak rumus yang harus dihapal dalam fisika. Salah satu topik yang dibahas dalam pembelajaran fisika di sekolah adalah fisika inti. Dalam era ini, begitu banyak perkembangan teknologi informasi yang dapat memecahkan permasalahan dalam pembelajaran. Dengan menggunakan komputer, seorang guru dapat memvisualisasikan materi fisika inti yang abstrak secara kasat mata. Sehingga, guru harus mampu menggunakan program sederhana seperti Adobe Flash, MATLAB, PhET, dan program-program lainnya untuk membantu pembelajaran.

Berdasarkan penelitian Jatmiko, B. et al (2013), dengan menerapkan simulasi PhET dan KIT sederhana pada siswa dapat mengajarkan keterampilan psikomotor siswa pada pokok bahasan alat optik. Meurut penelitian Hutagalung, S. N. (2018), pembelajaran fisika dasar dan elektronika dasar menggunakan program matlab dengan metode Simulink dapat membantu pemahaman kepada mahasiswa dalam memahami materi perkuliahan dalam bentuk simulasi. Berdasarkan penelitian Rajagukguk, J. dan Sarumaha, C. (2017), pembelajaran gerak parabola menggunakan aplikasi GUI matlab dapat 
memudahkan siswa dalam menggambarkan grafik gerak parabola.

Salah satu materi yang terdapat dalam Fisika Inti yaitu adalah mempelajari tentang atom. Atom merupakan satuan unit terkecil dari suatu unsur yang tidak dapat dibagi lagi. Inti atom terbagi menjadi dua, yakni inti atom yang bersifat stabil dan bersifat radiaoktif. Inti radioaktif akan memancarkan berupa radiasi $\alpha$, radiasi $\beta$, atau radiasi $\gamma$ dalam proses menuju kestabilan. Setiap atom yang memancarkan radiasi membutuhkan energi untuk memisahkan inti atom menjadi komponenkomponen nukleonnya. Energi ini disebut dengan energi ikat inti (Krane, 2012).

Unsur radioaktif yang pada umumnya didapatkan di alam merupakan anggota dari empat deret radioaktif. Deret Aktinium meruakan deret dengan nomor massa peluruhan yang memenuhi persamaan $4 n+3$ (Wiyatmo, 2012). Salah satu unsur deret aktinium, yakni Aktinium225 digunakan dalam pengobatan untuk menghasilkan $\mathrm{Bi}-213$ dalam generator yang dapat digunakan kembali atau dapat digunakan sendiri sebagai agen untuk radio-imunoterapi (Deblonde dan Abergel. 2016)

Penentuan suatu deret peluruhan radioaktif ke dalam deret Aktinium dibutuhkan penyelesaian peluruhan berantai untuk mengetahui nomor massa inti yang terbentuk tiap peluruhan nukleon. Salah satu penyelesaian yang dapat menyelesaikan persamaan tersebut yaitu dengan menggunakan simulasi komputer, berupa MATLAB. Sudah banyak penggunaan simulasi komputer pada kurikulum pendidikan teknik modern ini. Banyak buku teks yang menyajikan contoh-contoh dan latihan-latihan yang menggunakan program-program simulasi seperti MATLAB dan PSPICE. Menurut Jurado dan Keminskyj, penggunaan simulasi komputer telah membantu mahasiswa dalam pembelajarannya dan meningkatkan minat mahasiswa terhadap matakuliah yang diasuhnya (Antho 2011).
Selain itu, dalam mencari energi ikat dan energi disintegrasi yang dihasilkan oleh atom radioaktif menggunakan Model Tetes Cairan. Model Tetes Cairan yang dikembangkan oleh N. Bohr disebabkan karena adanya persamaan antara beberapa sifat inti dan tetes cairan. Salah satu persamaannya adalah kalor uap tetes cairan dengan energi ikat atau massa atom jumlah proton yang membentuk suatu tetesan cairan (Mahardika, 2008). Menurut penelitian Mardiana (2019), model inti tetesan cairan dapat menduga kestabilan inti suatu unsur dengan mempertimbangkan efek volume, efek permukaan, efek coloumb, efek asimetri dan efek pasangan di dalam suatu inti. Adapun tujuan dari penelitian ini yaitu menghitung energi ikat dan Energi Disintegrasi yang dihasilkan oleh peluruhan zat radioaktif pada deret Aktinium berdasarkan Model Inti Tetesan Cairan dengan telaah klasik.

\section{METODOLOGI PENELITIAN}

Penelitian ini menggunakan beberapa variabel diantaranya yaitu nomor massa dan atom unsur radioaktif, deret aktinium, energi ikat inti, energi disintegrasi, dan model tetes cairan. Langkah-langkah penelitian dapat dilihat pada Gambar 1 berikut:

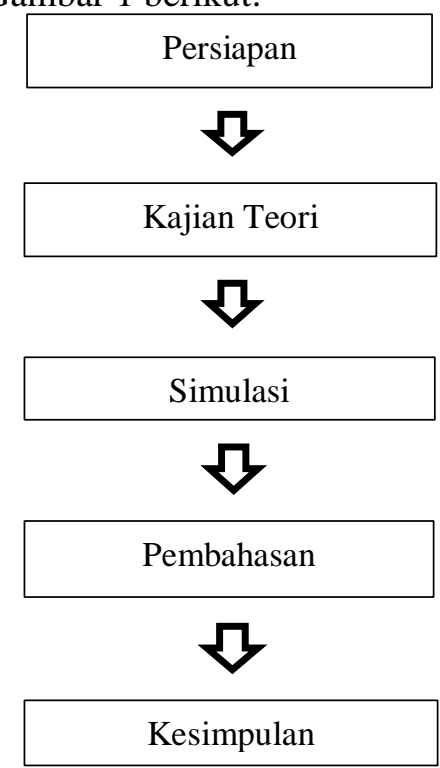

Gambar 1. Bagan langkah-langkah penelitian. 
Persiapan dilakukan dengan mencari bahan-bahan informasi dan studi literatur untuk menambah dan memperdalam pemahaman Kajian teori dilakukan dengan menggunakan studi literatur yang didapatkan mengenai simulasi peluruhan unsur radioaktif deret Aktinium, beserta energi ikat dan energi disintegrasi yang dihasilkan dalam penelitian. Tahap simulasi dengan model tetes cairan melakukan pengambilan data, dengan memasukkan persamaan energi ikat inti dan energi disintegrasi ke dalam pemrograman matlab. Persamaanpersamaan yang digunakan antara lain:

1. Persamaan Energi Ikat Model Tetesan Cairan

$$
\begin{gathered}
E=a_{v} A-a_{s} A^{2 / 3}-a_{c} Z^{2} A^{-1 / 3}-a_{a} \\
(A-2 Z) 2 A^{-1} \pm \delta(Z, A)
\end{gathered}
$$

Keterangan:

E : Energi Ikat

A : Nomor massaatom

$\mathrm{Z}$ : Nomor Atom

Dengan ketetapan koofisien:

$a_{v}=15,56 \mathrm{MeV}$

$a_{s}=17,23 \mathrm{MeV}$

$a_{c}=0,697 \mathrm{MeV}$

$a_{a}=23,285 \mathrm{MeV}$

$a_{p}=12 \mathrm{MeV}$

$\delta(Z, A)=0$, untuk A ganjil ( $\mathrm{Z}$ genap $\mathrm{N}$ ganjil atau $\mathrm{Z}$ ganjil-N genap)
$\delta(Z, A)=+a_{p} / A^{1 / 2}$, untuk $\mathrm{A}$ genap ( $\mathrm{Z}$ genap - $\mathrm{N}$ genap)

$\delta(Z, A)=-a_{p} / A^{1 / 2}$ untuk A genap $(\mathrm{Z}$ ganjil-N ganjil. (Gautreau, R. dan Savin, W., 2006)

2. Persamaan Energi Disintegrasi

$Q_{\alpha}=E_{B(Y)}+E_{B(\alpha)}-E_{B(X)}$

$Q_{\beta}=E_{B(Y)}-E_{B(X)}+m_{n}-m_{H}$

Keterangan:

$Q_{\alpha} \quad$ : energi disintegrasi alfa

$E_{B(Y)}$ : energi ikat inti nuklida turunan

$E_{B(X)}$ : energi ikat nuklida induk

$E_{B(\alpha)}$ : energi ikat partikel alfa

$Q_{\beta} \quad$ : energi disintegrasi beta

$m_{n}$ : massa neutron $(939,573 \mathrm{MeV})$

$m_{H}$ : massa atom hidrogen $(938,791$

$\mathrm{MeV}$ )

Pada tahap pembahasan dilakukan secara runtun mengenai hasil analisa peluruhan unsur radioaktif deret aktinium, beserta energi ikat dan energi disintegrasi yang dihasilkan. Terakhir adalah tahap kesimpulan yang berisikan hasil analisis dan pembahasan untuk menjawab rumusan masalah penelitian.

\section{HASIL DAN PEMBAHASAN}

Hasil penelitian peluruhan Deret Aktinium dengan menggunakan Model Tetesan Cairan dapat dilihat pada Tabel 1 berikut:

Tabel 1. Hasil Perhitungan $E_{v}, E_{s}, E_{c}, E_{a}$, dan $E_{p}$ Unsur Radioaktif Deret Aktinium

\begin{tabular}{|c|c|c|c|c|c|c|c|}
\hline No & Nama Unsur & $\begin{array}{l}\text { Lam } \\
\text { bang }\end{array}$ & $\begin{array}{c}E_{v} \\
(\mathrm{MeV})\end{array}$ & $\begin{array}{c}E_{s} \\
(\mathrm{MeV})\end{array}$ & $\begin{array}{c}E_{c} \\
(\mathrm{MeV})\end{array}$ & $\begin{array}{c}E_{a} \\
(\mathrm{MeV})\end{array}$ & $\begin{array}{c}E_{p} \\
(\mathrm{MeV})\end{array}$ \\
\hline 1 & $\begin{array}{c}\text { Actinouranium } \\
\text { (AcU) }\end{array}$ & ${ }_{92} U^{235}$ & 3656.6 & 656.141 & 955.9881 & 257.7204 & 0 \\
\hline 2 & $\begin{array}{l}\text { Uranium Y } \\
\text { (UY) }\end{array}$ & ${ }_{90} T h^{23 I}$ & 3594.36 & 648.6742 & 920.1256 & 262.1831 & 0 \\
\hline 3 & $\begin{array}{l}\text { Protactinium } \\
\qquad(\mathrm{Pa})\end{array}$ & ${ }_{91} \mathrm{~Pa}^{231}$ & 3594.36 & 648.6742 & 940.6865 & 242.0229 & -0.78954 \\
\hline 4 & Actinium (Ac) & ${ }_{89} A c^{227}$ & 3532.12 & 641.1641 & 905.0464 & 246.2876 & -0.79647 \\
\hline 5 & $\begin{array}{l}\text { Radioactini- } \\
\text { um (RdAc) }\end{array}$ & ${ }_{90} T h^{227}$ & 3532.12 & 641.1641 & 925.4988 & 226.5928 & 0 \\
\hline 6 & $\begin{array}{l}\text { Actinium K } \\
(\mathrm{AcK})\end{array}$ & ${ }_{87} \mathrm{Fr}^{223}$ & 3469.88 & 633.6098 & 869.9674 & 250.7053 & -0.80358 \\
\hline
\end{tabular}
dengan Model Tetesan Cairan 


\begin{tabular}{|c|c|c|c|c|c|c|c|}
\hline 7 & $\begin{array}{c}\text { Actinium } X \\
(\mathbf{A c X})\end{array}$ & ${ }_{88} R a^{223}$ & 3469.88 & 633.6098 & 890.0816 & 230.6572 & $\mathbf{0}$ \\
\hline 8 & Astatine 219 & ${ }_{85} A t^{219}$ & 3407.64 & 626.0101 & 835.4541 & 255.2844 & -0.81088 \\
\hline 9 & $\begin{array}{l}\text { Ac Emanation } \\
\text { (An) }\end{array}$ & ${ }_{86} \mathrm{Em}^{219}$ & 3407.64 & 626.0101 & 855.2275 & 234.8702 & 0 \\
\hline 10 & Bismuth 215 & ${ }_{83} B i^{215}$ & 3345.4 & 618.3641 & 801.511 & 260.0339 & -0.81839 \\
\hline 11 & $\begin{array}{c}\text { Actinium A } \\
(\mathrm{AcA})\end{array}$ & ${ }_{84} \mathrm{Po}^{215}$ & 3345.4 & 618.3641 & 820.9408 & 239.2398 & 0 \\
\hline 12 & $\begin{array}{l}\text { Actinium B } \\
\text { (AcB) }\end{array}$ & ${ }_{82} P b^{211}$ & 3283.16 & 610.6705 & 787.2264 & 243.7752 & 0 \\
\hline 13 & Astatine 215 & ${ }_{85} A t^{215}$ & 3345.4 & 618.3641 & 840.6034 & 219.3122 & -0.81839 \\
\hline 14 & $\begin{array}{l}\text { Actinium C } \\
\text { (AcC) }\end{array}$ & ${ }_{83} B i^{211}$ & 3283.16 & 610.6705 & 806.5441 & 223.4698 & -0.8261 \\
\hline 15 & $\begin{array}{c}\text { Actinium } C^{\prime} \\
\left(\text { AcC }^{\prime}\right)\end{array}$ & ${ }_{84} \mathrm{Po}^{211}$ & 3283.16 & 610.6705 & 826.096 & 204.0472 & 0 \\
\hline 16 & $\begin{array}{l}\text { Actinium C', } \\
\left(\text { AcC }^{\prime \prime}\right)\end{array}$ & ${ }_{81} T l^{207}$ & 3220.92 & 602.9281 & 773.0591 & 227.788 & -0.83406 \\
\hline 17 & Actinium D & ${ }_{82} P b^{207}$ & 3220.92 & 602.9281 & 792.2648 & 207.9902 & 0 \\
\hline
\end{tabular}

Tabel 2. Hasil Perhitungan Energi Ikat dan Energi Disintegrasi Unsur Radioaktif Deret Aktinium dengan Model Tetesan Cairan

\begin{tabular}{|c|c|c|c|c|c|c|}
\hline No & Nama Unsur & Lam bang & $\mathbf{N} / \mathbf{P}$ & $\begin{array}{c}\mathrm{E} \\
(\mathrm{MeV})\end{array}$ & $\begin{array}{c}\text { E/A } \\
(\mathrm{MeV})\end{array}$ & $\begin{array}{c}\mathbf{Q} \\
(\mathrm{MeV})\end{array}$ \\
\hline 1 & $\begin{array}{c}\text { Actinouranium } \\
\text { (AcU) }\end{array}$ & ${ }_{92} U^{235}$ & 1.554 & 1786.751 & 7.6032 & 4.5116 \\
\hline 2 & Uranium Y (UY) & ${ }_{90} T h^{231}$ & 1.567 & 1762.967 & 7.6319 & 0.0018 \\
\hline 3 & Protactinium $(\mathrm{Pa})$ & ${ }_{91} \mathrm{~Pa}^{231}$ & 1.538 & 1762.187 & 7.6285 & 4.9335 \\
\hline 4 & Actinium (Ac) & ${ }_{89} A c^{227}$ & 1.551 & 1738.826 & 7.66 & 0.8209 \\
\hline 5 & $\begin{array}{l}\text { Radioactini-um } \\
(\mathrm{RdAc})\end{array}$ & ${ }_{90} T h^{227}$ & 1.522 & 1738.864 & 7.6602 & 4.2246 \\
\hline 6 & Actinium K (AcK) & ${ }_{87} F r^{223}$ & 1.563 & 1714.794 & 7.6897 & 1.5195 \\
\hline 7 & Actinium X (AcX) & ${ }_{88} R a^{223}$ & 1.5341 & 1715.531 & 7.693 & 4.2959 \\
\hline 8 & Astatine 219 & ${ }_{85} A t^{219}$ & 1.576 & 1690.081 & 7.7173 & 2.8872 \\
\hline 9 & $\begin{array}{c}\text { Ac Emanation } \\
\text { (An) }\end{array}$ & ${ }_{86} \mathrm{Em}^{219}$ & 1.547 & 1691.532 & 7.7239 & 3.618 \\
\hline 10 & Bismuth 215 & ${ }_{83} B i^{215}$ & 1.59 & 1664.673 & 7.7427 & 2.9646 \\
\hline 11 & Actinium A (AcA) & ${ }_{84} \mathrm{Po}^{215}$ & 1.56 & 1666.855 & 7.7528 & 2.9277 \\
\hline 12 & Actinium B (AcB) & ${ }_{82} P b^{211}$ & 1.573 & 1641.488 & 7.7796 & 0.9436 \\
\hline 13 & Astatine 215 & ${ }_{85} A t^{215}$ & 1.529 & 1666.302 & 7.7502 & 3.6426 \\
\hline No & Nama Unsur & Lam bang & $\mathrm{N} / \mathrm{P}$ & $\begin{array}{c}\mathrm{E} \\
(\mathrm{MeV})\end{array}$ & $\begin{array}{c}\text { E/A } \\
(\mathrm{MeV})\end{array}$ & $\begin{array}{c}\mathrm{Q} \\
(\mathrm{MeV})\end{array}$ \\
\hline 14 & Actinium C (AcC) & ${ }_{83} B i^{211}$ & 1.542 & 1641.65 & 7.7803 & 2.9562 \\
\hline 15 & $\begin{array}{l}\text { Actinium C' } \\
\text { (AcC') }\end{array}$ & ${ }_{84} \mathrm{Po}^{211}$ & 1.512 & 1642.346 & 7.7836 & 3.6857 \\
\hline 16 & $\begin{array}{c}\text { Actinium C', } \\
\left(\text { AcC }^{\prime} "\right)\end{array}$ & ${ }_{81} T l^{207}$ & 1.556 & 1616.311 & 7.8083 & 2.2082 \\
\hline 17 & Actinium D & ${ }_{82} \mathrm{~Pb}^{207}$ & 1.524 & 1617.737 & 7.8152 & Stabil \\
\hline
\end{tabular}

Dengan keterangan:

E : Energi ikat $(\mathrm{MeV})$

Q : Energi disintegrasi $(\mathrm{MeV})$

$\mathrm{N} / \mathrm{P}$ :Perbandingaan antara neutron dan proton

E/A: Efek ikat per nuklen $(\mathrm{MeV})$
$E_{v}$ : Efek volume (MeV)

$E_{S}$ : Efek permukaan $(\mathrm{MeV})$

$E_{c}$ : Efek coloumb (MeV)

$E_{a}$ : Efek asimetri (MeV)

$E_{p}$ : Efek pasangan $(\mathrm{MeV})$ 

Selain itu dapat dilihat grafik hubungan antara Massa atom (A) dengan Energi Ikat (E) dan Energi Disintegrasi (Q) yang dilepaskan selama peluruhan unsur
Radioaktif deret Aktinium sebagaimana ditunjukkan pada Gambar 1 berikut.

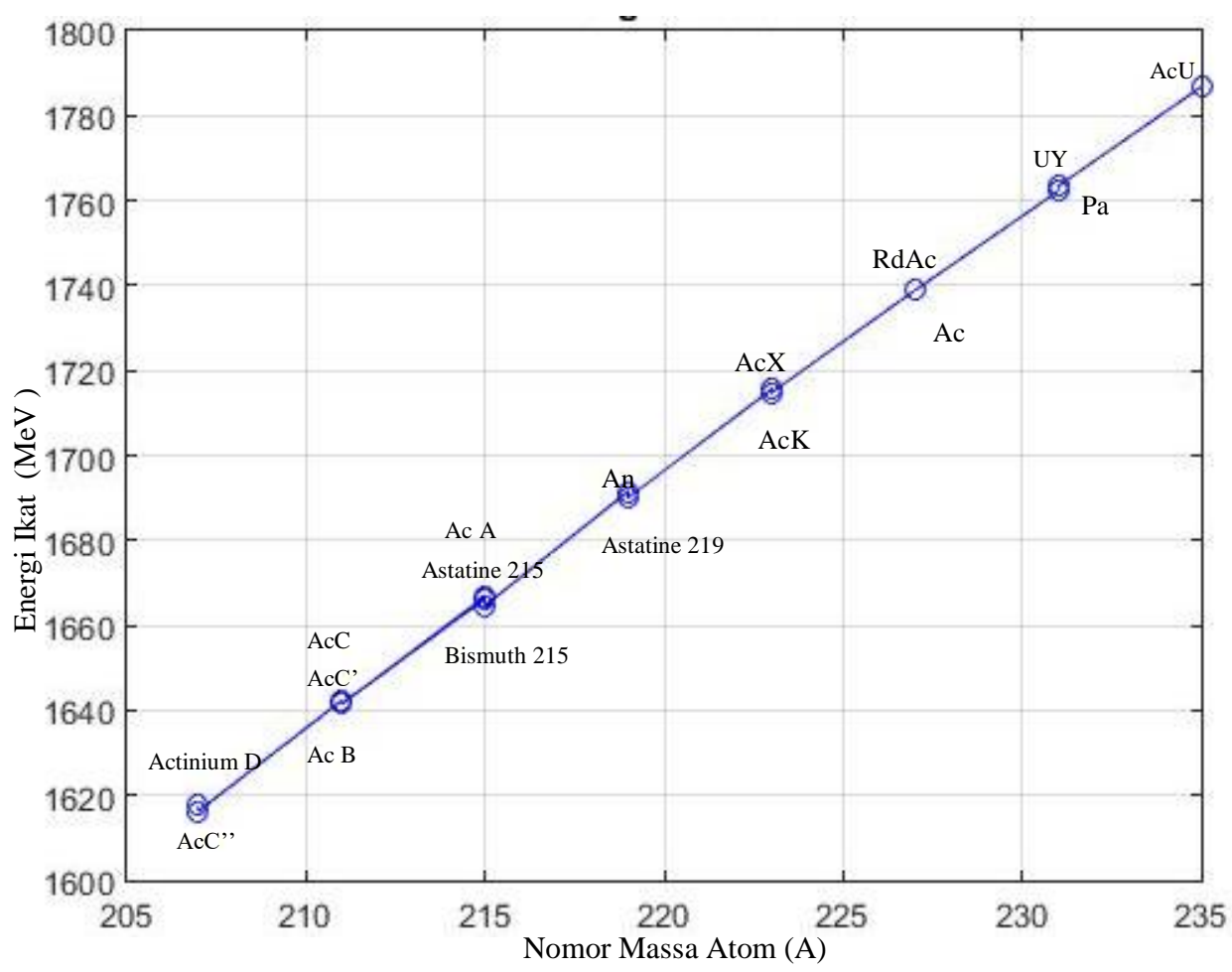

Gambar 1. Grafik Energi Ikat Deret Aktinium Unsur Radioaktif

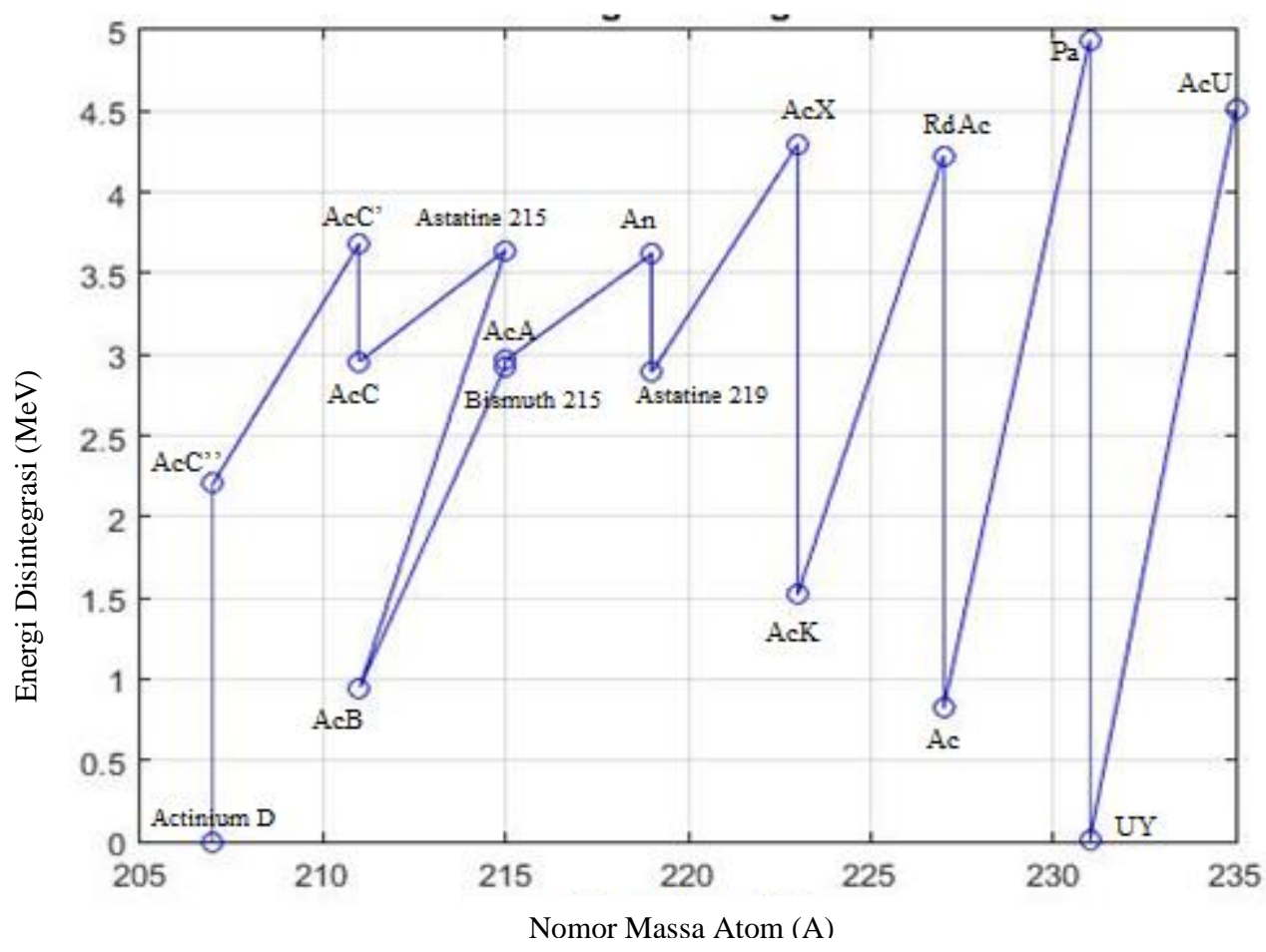

Gambar 2. Grafik Energi Disintegrasi Deret Aktinium Unsur Radioaktif 
Berdasarkan penelitian yang telah dilakukan oleh peneliti di laboratorium komputer Program Pendidkan Fisika FKIP Universitas Jember, yaitu membuat simulasi peluruhan unsur radioaktif deret Aktinium. Adapun hasil simulasi yang ditemukan adalah besar energi ikat (E) dan energi disintegrasi $(\mathrm{Q})$ dengan nilai ratarata ketidakpastian relatif (KR) sebesar $0,02252 \%$ untuk energi ikat dan 0,22633\% untuk energi disintegrasi, dimana nilai tersebut berada dibawah $0,5 \%$. Unsur Aktinium termasuk unsur radioaktif alami dari hasil peluruhan radioaktif ${ }_{92} U^{235}$ yang belum stabil dan berakhir menghasilkan produk akhir stabil berupa Timbal-207. Deret Aktinium menghasilkan radioaktif induk berupa ${ }_{92} U^{235}$ dan memiliki waktu paruh $7,10 \times 10^{8}$ tahun. Dalam deret aktinium mengalami 16 proses peluruhan berupa 10 peluruhan alfa $(\alpha)$ dan 6 peluruhan beta $(\beta)$.

Jika dilihat pada Gambar 1, nilai energi ikat menggunakan model tetesan cairan yang dihasilkan unsur radioaktif deret Aktinium mengalami penurunan secara linier. Semakin kecil nomor massanya (A) maka akan semakin kecil pula energi ikat (E) yang diperlukan dalam melakukan peluruhan. Hal ini dikarenakan semakin kecil nilai massa nukleon dan nuklida berat akan mendekati kestabilan menuju nuklida sedang, maka semakin kecil energi ikatnya. Seperti yang dijelaskan dalam percobaan C.F von Weizsacker bahwa pada model tetesan cairan, kerapatan konstan dan energi ikat berbanding lurus dengan massa dan jumlah partikel yang membentuk tetesan.

Energi ikat tebesar dimiliki oleh unsur ${ }_{92} U^{235}$ yaitu sebesar $1786,751 \mathrm{MeV}$ dan energi ikat terkecil dimiliki oleh unsur ${ }_{81} T l^{207}$ sebesar 1616,311 MeV. Energi ikat tekecil tidak dimiliki oleh unsur ${ }_{82} \mathrm{~Pb}^{207}$ yang merupakan unsur terakhir pada deret Aktinium. Hal ini dikarenakan jumlah proton unsur ${ }_{82} \mathrm{~Pb}^{207}$ lebih besar dan benrilai genap sehingga memengaruhi energi asimetri dan energi coloumb yang bernilai lebih kecil diabanding unsur
${ }_{81} T l^{207}$. Nilai energi asimetri yang kecil dan energi coloumb nol (0), akan menghasilkan energi ikat yang lebih besar. Pada peluruhan alfa mengalami penurunan energi ikat cukup besar, namun pada peluruhan beta energi ikat mengalami penurunan dan kenaikan cukup kecil seperti yang digambarkan pada Gambar 1 . Hasil yang didapatkan sesuai dengan penelitian Mardiana (2019). Hal inni dikarenakan partikel alfa memiliki massa terbesar, kira-kira empat kali massa proton atau neutron dan kira-kira 8.000 kali massa partikel beta. Karena massa partikel alfa yang besar, maka memiliki kekuatan pengion tertinggi dan kemampuan terbesar untuk merusak jaringan.

Seluruh energi disintegrasi yang ditemukan pada Tabel 2. memiliki nilai positif, sehingga hal ini sesuai dengan syarat tejadinya peluruhan yaitu Q $>0$. Menurut Wiyatmo (2012), peluruhan akan terjadi jika memenuhi syarat syarat yaitu $Q>0$, sehingga $m_{(x)}>$

$m_{(y)}$ (peluruhan dapat terjadi dengan massa atomik nuklida induk lebih besar dari massa atomik nuklida turunan) atau dengan artian lain energi disintegrasi memiliki nilai positif yang lebih dari nol $(\mathrm{Q}>0)$. Energi disintegrasi tebesar dihasilkan dari peluruhan alfa oleh unsur ${ }_{91} \mathrm{~Pa}^{231}$ yaitu sebesar $4,9335 \mathrm{MeV}$ dan energi ikat terkecil dihasilkan dari peluruhan beta oleh unsur ${ }_{90} T h^{231}$ yaitu sebesar $0,0018 \mathrm{MeV}$. Unsur ${ }_{82} \mathrm{~Pb}^{207}$ adalah unsur tidak menghasilkan energi disintegrasi karena merupakan unsur stabil yang tidak membutuhkan peluruhan.

\section{KESIMPULAN DAN SARAN}

Berdasarkan hasil penelitian yang telah dilakukan dapat disimpulkan yaitu nilai energi ikat yang dihasilkan unsur radioaktif Deret Aktinium dengan Model Tetes Cairan sesuai dengan teori dimana energi ikat berbanding lurus dengan massa dan jumlah partikel yang membentuk tetesan. Pada peluruhan alfa mengalami penurunan energi ikat cukup besar, namun pada peluruhan beta energi ikat 
mengalami penurunan dan kenaikan cukup kecil. Energi ikat menggunakan model tetesan cairan yang dimiliki oleh unsur ${ }_{92} U^{235}$ untuk mencapai suatu kestabilan yakni sebesar 1786,751 MeV. Sedangkan unsur energi ikat terkecil dimiliki oleh unsur ${ }_{81} \mathrm{Tl}^{207}$ dengan nilai sebesar 1616,311 MeV.

Energi disintegrasi yang ditemukan pada unsur radioaktif Deret Aktinium memiliki nilai positif, sehingga hal ini sesuai dengan syarat tejadinya peluruhan yaitu Q>0. Energi disintegrasi tebesar dihasilkan dari peluruhan alfa oleh unsur ${ }_{91} \mathrm{~Pa}^{231}$ yaitu sebesar $4,9335 \mathrm{MeV}$ dan energi ikat terkecil dihasilkan dari peluruhan beta oleh unsur ${ }_{90} T h^{231}$ yaitu sebesar $0,0018 \mathrm{MeV}$. Unsur ${ }_{82} \mathrm{~Pb}^{207}$ adalah unsur tidak menghasilkan energi disintegrasi karena merupakan unsur stabil yang tidak membutuhkan peluruhan.

Saran yang dapat disampaikan pada penelitian ini yaitu: 1) penelitian selanjutnya dapat mengkaji dan membuat simulasi dengan model inti atau unsur radioaktif yang berbeda sehingga dapat memperluas studi literatur mengenai fisika inti yang dapat diajarkan di sekolah maupun perguruan tinggi; 2) energi disintegrasi yang dapat dikaji tidak hanya menggunakan telaah klasik, namun juga dapat ditelaah menggunakan telaah modern untuk membedakan perbedaan hasil keduanya; dan 3) peneliti selanjutnya tidak hanya dapat membuat simulasi Matlab, namun membuat sebuah program untuk mengkalkulasikan nilai energi ikat dan energi disintegrasi yang dihasilkan oleh unsur radioaktif dalam sebuah peluruhan.

\section{DAFTAR RUJUKAN}

Antho, B. 2011. Pemodelan Dan Simulasi Berbasis Matlab/Simulink Terhadap Gerakan Rotor Motor Stepper 3Fasa Jenis Variable Reluctance. Jurnal Sains, Teknologi dan Industri. 10(1): 44.

Deblonde, G. dan R. J. Abergel. 2016. Active Actinium. Nature Chemistry. 8: 1084 .
Gauterau, R. dan W. Savin. 2006. Fisika

Modern Edisi Kedua. Jakarta: Erlangga.

Hutagalung, S. H. 2018. Pembelajaran Fisika Dasar dan Elektronika Dasar Menggunakan Aplikasi Matlab

Metode Simulink. Journal of Science and Social Research. 1(1): 31-32.

Jatmiko, B., Prastowo, T., Prihatiningtyas, S. 2013. Implementasi Simulasi Phet dan Kit Sederhana untuk Mengajarkan Keterampilan Psikomotor Siswa pada Pokok Bahasan Alat Optik. Jurnal Pendidikan IPA Indonesia. 2(1): 1920.

Krane, K. 2012. Fisika Modern. Jakarta: Universitas Indonesia.

Mahardika, I K. 2008. Sifat-Sifat, Energi Ikat, dan Sistem Nukleon "Dalam Pendahuluan Fisika Inti. Jember: Fakultas Keguruan dan Ilmu Pendidikan Universitas Jember.

Mardiana I, I., T. Prihandono, dan Yushardi. 2019. Kajian Kestabilan Inti Unsur-Unsur Pada Proses Peluruhan Zat Radioaktif dengan Pendekatan Energi Ikat Inti Model Tetes Cairan. Jurnal Pembelajaran Fisika. 8(2):101-106.

Rajagukguk, J. dan Sarumaha, C. 2017. Pemodelan dan Analisis Gerak Parabola Dua Dimensi dengan Menggunakan Aplikasi GUI Matlab. Jurnal Saintika. 17(2): 63.

Wiyatmo,Y. 2012 . Fisika Nuklir: Dalam Telaah Klasik dan Kuantum. Yogyakarta: Pustaka Pelajar. 